\title{
Targeted Next-Generation Sequencing of MLH1, MSH2, and MSH6 Genes in Patients with Endometrial Carcinoma under 50 Years of Age
}

\author{
Taha Reşid Özdemir1 ${ }^{1}$, Murat Alan², Muzaffer Sanc12, Altuğ Koç1 \\ ${ }^{1}$ Genetic Diagnostic Center, Health Sciences University, İzmir Tepecik Training and Research Hospital, İzmir, Turkey \\ ${ }^{2}$ Clinic of Gynecology and Gynecologic Oncology, Health Sciences University, İzmir Tepecik Training and Research Hospital, İzmir, Turkey
}

Background: Lynch syndrome is an inherited cancer disorder that causes an increased lifetime risk of various types of cancers. Endometrial cancer is the most common extracolonic cancer in Lynch syndrome. Guidelines recommend that patients with endometrial cancer younger than 50 years of age should be evaluated for Lynch syndrome. Molecular analysis of the mismatch repair genes and EPCAM gene is required for a definitive diagnosis of Lynch syndrome.

Aims: To report the mutation analysis of mismatch repair genes using targeted next-generation sequencing in endometrial cancer diagnosed patients $<50$ years of age.

Study Design: Retrospective cross-sectional study.

Methods: Seventy-nine endometrial cancer diagnosed patients $<50$ years of age underwent genetic counseling. They were selected among 1094 consecutive endometrial cancer patients between 2006 and 2017. Molecular analysis of $M L H 1, M S H 2$, and MSH6 genes was performed in 79 patients by using next-generation sequencing. Deletion/duplication analysis of mismatch repair genes and EPCAM gene was also performed in 79 patients by using the multiplex ligationdependent probe amplification method.

Results: Germline testing of mismatch repair genes was performed in 79 endometrial cancer patients. Lynch syndrome was confirmed in 4 patients $(5 \% ; 4 / 79)$. A total of 14 variants (6 in $M S H 2,5$ in $M L H 1,3$ in MSH6 genes) were found in 14 patients. Four variants were assessed as pathogenic/likely pathogenic, and 10 variants were assessed as variants of uncertain significance.

Conclusion: Lynch syndrome should be investigated in patients diagnosed with endometrial cancer that are less than 50 years of age due to the increased lifetime risk of developing cancer.

Keywords: Endometrial carcinomas, Lynch syndrome, mismatch repair, sequence analysis
Lynch syndrome is an autosomal dominant disorder that causes colorectal cancer, endometrial cancer, and upper gastrointestinal tract cancers among others. Lynch syndrome occurs when there is a germline mutation in $M L H 1, M S H 2, M S H 6, P M S 2$, [mismatch repair (MMR) genes] and the EPCAM gene. The frequency of mutation carriers in MMR genes is estimated to be 1:279 (1).

There are several criteria to identify individuals at risk for Lynch syndrome. These include clinical and pathologic criteria (e.g. Amsterdam criteria, revised Bethesda criteria), tumor testing [microsatellite instability, immunohistochemistry (IHC) testing], and prediction models $\left(\mathrm{PREMM}_{5}\right.$ model, MMRpredict model, MMRpro model).

Endometrial cancer is the most common extracolonic cancer in Lynch syndrome that accounts for 2 to $5 \%$ of all endometrial cancers $(2,3)$. The women with Lynch syndrome have an increased cancer risk during their lifetime for endometrial cancer (25-60\%), colorectal cancer (40-80\%), and ovarian cancer (4-24\%) (4). According to the American College of Medical Genetics and Genomics (ACMG) and the National Society of Genetic Counselors (NSGC) guideline (4), patients diagnosed with endometrial cancer younger than 50 years of age should be evaluated for Lynch syndrome. In these patients, performing a germline testing in MMR genes confirms the diagnosis and it could guide the clinical treatment. In addition, it could provide a mutation screening for asymptomatic relatives who will be at $50 \%$ risk of inheriting the mutation.

In our study, the molecular analysis of MMR genes was performed using targeted next-generation sequencing (NGS). This provides simultaneous analysis of multiple genes in a single test, in patients diagnosed with endometrial cancer younger than 50 years of age, to present the frequency of germline mutations in MMR genes. To our knowledge, this is the first study of this kind in Turkey.

\section{MATERIALS AND METHODS}

\section{Patients}

The ethical committee approved this study as a retrospective study, and informed consent was obtained from the patients studied.

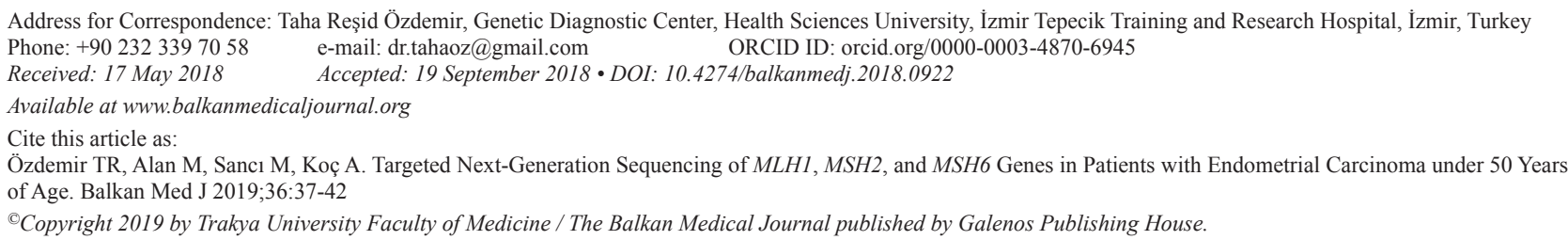


The gynecologic-oncology department reviewed the files of patients with endometrial cancer between the years 2006-2017. They identified 79 patients diagnosed with endometrial cancer younger than 50 years of age among 1094 patients. Seventy-nine patients were directed to the genetic diagnostic center for genetic counseling. When the patients' records were examined, it was noticed that the IHC or microsatellite instability testing was not requested. After the family history was reviewed for each patient, the $\mathrm{PREMM}_{5}$ prediction model was used to predict the probability of a patient carrying a germline mutation in the MMR genes, or EPCAM gene (5).

\section{Targeted NGS}

After genomic DNA samples were obtained, targeted NGS was performed with the Illumina MiSeq NGS System (Illumina Inc., San Diego, CA, USA) using a Miseq Reagent Kit v2 (500-cycles) (Catalog No: MS-102-2003. Illumina Inc., San Diego, CA, USA). The NEXTflex ${ }^{\circledR}$ Colorectal Cancer Amplicon Panels for the Illumina ${ }^{\circledR}$ platforms (Bioo Scientific Corp., Austin, TX, USA) were used to reveal variants in the coding regions and in the intronic regions (up to the area covered by the kit) of $M L H 1, M S H 2$, and MSH6 genes. Analysis of the PMS2 gene was excluded from the study due to a large number of pseudogenes belonging to this gene.

\section{NGS data analysis}

The raw data obtained with the NGS method was analyzed using the 'SEQ variant analysis software' (Genomize, İstanbul, Turkey) according to the reference genome of GRCh37 (hg19) [RefSeqID's: MLH1 (NM_000249), MSH2 (NM_000251), MSH6 (NM_000179)]. The SEQ software demonstrated that the minimum coverage-depth of the target regions was $100 \mathrm{X}$. These were evaluated using the Integrative Genomics Viewer software $(6,7)$. Variants were determined based on 50X coverage-depth per allele (reference allele/alternative allele) and they were filtered according to following criteria:

- Exclusion of benign (B)/likely benign variants from all the submissions in the ClinVar database,

- Exclusion of variants that had an allele frequency $>5 \%$ in any of the population databases (ESP or 1000 Genomes or ExAC),

- The inclusion of variants in the coding regions and in the intronic regions.

Lastly, filtered variants were evaluated according to the ACMG Standards and Guidelines recommendations (8). Several databases and in-silico prediction tools were used for interpreting these variants (9-13).

\section{Confirmation and Multiplex ligation-dependent probe amplification analyses}

The ACMG Standards and Guidelines (8) recommend performing confirmation studies for all sequence variants that are considered to be pathogenic or likely pathogenic. Therefore, Sanger sequencing was performed in patients with variants that were considered to be pathogenic or likely pathogenic. After NGS analysis, multiplex ligation-dependent probe amplification (MLPA) analysis was performed using SALSA ${ }^{\circledR}$ MLPA ${ }^{\circledR}$ probemix P003-D1 MLH1/ MSH2, P072-C1 MSH6 kits (MRC-Holland, Amsterdam,
The Netherlands) in patients who had no pathogenic or likely pathogenic variants.

\section{RESULTS}

Molecular analysis of MMR genes was performed in 79 patients with endometrial cancer. The mean age at diagnosis for all the patients was 44.4 years, with a range of 22 to 49 years. The mean age at diagnosis for four patients with pathogenic/likely pathogenic variants was 42.5 (range 35 to 48 years). Family history and pathologic features of patients with identified variants are presented in Table 1.

Fourteen different variants were identified in 14 patients $(18 \%$; 14/79) (Table 2). Four variants were assessed as pathogenic or likely pathogenic that were confirmed using Sanger sequencing. Thus, Lynch syndrome diagnosis was confirmed in 4 patients $(5 \%$; 4/79). Ten variants were assessed as 'variants of uncertain significance'. All of the variants were found to be heterozygous. Three variants were interpreted as pathogenic and one was interpreted as likely pathogenic $(5 \% ; 4 / 79)$. One of the pathogenic variants (in the $M L H 1$ gene) was previously reported in the literature $(14,15)$. The others were evaluated as a novel (1 in MLH1 and 2 in MSH2). Four variants in MSH2, 3 variants in $M L H 1$, and 3 variants in MSH6 genes were found and evaluated as variants of uncertain significance.

No deletion or duplication was detected in $\mathrm{MLH1}$, MSH2, MSH6 genes, and EPCAM gene.

\section{DISCUSSION}

Several criteria, such as the Amsterdam and Bethesda criteria, are used to identify cases at risk for Lynch syndrome in endometrial cancer patients; however, not all the patients with Lynch syndrome meet these criteria. The mean age at diagnosis is between 46 and 54 years in endometrial cancer patients with Lynch syndrome (16). In addition, a significant proportion (10\%) of endometrial cancer patients with Lynch syndrome is diagnosed at an age younger than 50 years of age (17). Therefore, patients with endometrial cancer diagnosed less than 50 years of age were evaluated for Lynch syndrome in our study and the ACMG and NSGC guideline were considered. For this purposes, we performed molecular analysis of MMR genes (MLH1, MSH2, and MSH6 genes) by using targeted NGS that provides a simultaneous analysis of genes at a comparable cost to Sanger sequencing.

Two novel variants in the MSH2 gene were identified in this study. The first novel variant was an inframe deletion that was found between 416-418 nucleotides position. There was a known disease mutation at the 416. nucleotide position [c.416delA(p. N139Mfs*35)](HGMD:CD056196), three nucleotide deletions were found in our study. The second was a frameshift variant consisting of five nucleotides deletion that affected the 744 . amino acid position. There was a mutation consisting of a single nucleotide change in the same codon that was previously reported [c.2231T $>$ G(p.L744*)](HGMD: CM117434). One novel variant in $M L H 1$ gene was found in the donor splice site of the intron7 (NM_000249:c.588+1G $>$ A) (Figure 1a, 1b). There 
TABLE 1. Summary of patients family history and pathologic features of patients with an identified variations $(n=14)$

\begin{tabular}{|c|c|c|c|c|c|c|c|c|c|}
\hline Patient & Age & $\begin{array}{c}\text { Age at } \\
\text { diagnosis }\end{array}$ & $\begin{array}{l}\text { First-Degree Relatives (LS- } \\
\text { associated cancer) }\end{array}$ & $\begin{array}{l}\text { Second-Degree Relatives } \\
\text { (LS-associated cancer) }\end{array}$ & $\begin{array}{l}\text { PREMM5 } \\
\text { scores }\end{array}$ & Stage & Histology & $\begin{array}{l}\text { FIGO } \\
\text { grade }\end{array}$ & Location \\
\hline 46 & 51 & 48 & $\begin{array}{c}\text { 1- Mother: CRC } \\
\text { (34 at diagnosis, } 34 \text { ex) } \\
\text { 2- Brother: CRC } \\
\text { (34 at diagnosis, } 34 \text { ex) }\end{array}$ & None & $23.2 \%$ & pT1b & Endometrioid & 2 & Corpus \\
\hline 26 & 44 & 40 & $\begin{array}{c}\text { 1- Mother: Gastric CA (37 at } \\
\text { diagnosis, } 38 \mathrm{ex} \text { ) }\end{array}$ & $\begin{array}{l}\text { 1- Grandmother: CRC } \\
\text { (48 at diagnosis, } 50 \text { ex) } \\
\text { 2- Aunt: CRC } \\
\text { (38 at diagnosis, } 40 \text { ex) }\end{array}$ & $7.7 \%$ & pT1b & Endometrioid & 2 & Corpus \\
\hline 3 & 50 & 47 & None & None & $2.9 \%$ & $\mathrm{pT} 3 \mathrm{c}$ & Endometrioid & 3 & Corpus \\
\hline 18 & 35 & 35 & None & None & $4 \%$ & pT2 & Endometrioid & 2 & LUS \\
\hline 1 & 48 & 45 & None & None & $3 \%$ & pT1a & Endometrioid & 1 & Corpus \\
\hline 57 & 34 & 22 & None & None & $4 \%$ & pT1b & Endometrioid & 2 & Corpus \\
\hline 4 & 55 & 49 & None & None & $2.6 \%$ & pT1b & Endometrioid & 2 & Corpus \\
\hline 71 & 58 & 45 & None & None & $2.3 \%$ & $\mathrm{pT} 1 \mathrm{~b}$ & Endometrioid & 2 & Corpus \\
\hline 10 & 43 & 43 & $\begin{array}{l}\text { 1- Father: Gastric CA } \\
\text { (60 at diagnosis, } 60 \mathrm{ex} \text { ) }\end{array}$ & None & $4.6 \%$ & pT3c & Endometrioid & 3 & LUS \\
\hline 54 & 52 & 47 & None & None & $2.7 \%$ & pT1a & Endometrioid & 1 & Corpus \\
\hline 36 & 45 & 41 & $\begin{array}{c}\text { 1- Father: CRC } \\
\text { (80 at diagnosis, } 85 \text { ex) }\end{array}$ & None & $2.8 \%$ & pT1a & Endometrioid & 1 & Corpus \\
\hline 66 & 58 & 47 & None & None & $2.3 \%$ & pT1a & Endometrioid & 2 & Corpus \\
\hline 65 & 61 & 48 & None & None & $2.2 \%$ & pT1a & Endometrioid & 2 & Corpus \\
\hline 45 & 42 & 38 & None & None & $3.3 \%$ & pT1b & Endometrioid & 3 & LUS \\
\hline
\end{tabular}

TABLE 2. Classification of variants identified $(n=14)$

\begin{tabular}{|c|c|c|}
\hline Patient & Identified variants & Evaluated as \\
\hline 46 & MLH1:NM_00029:c.588+1G>A(Intron7) Heterozygous & Pathogenic (novel) \\
\hline 26 & MLH1:NM_000249:c.1009_1010insC(c.1011dupC)(p.N338Qfs*24)(Exon11) Heterozygous & Pathogenic (known) \\
\hline 3 & MSH2:NM_000251:c.416_418delATG(p.D140del)(Exon3) Heterozygous & Likely Pathogenic (novel) \\
\hline 18 & MSH2:NM_000251:c.2230_2234delTTAAT(p.L744Nfs*4)(Exon14) Heterozygous & Pathogenic (novel) \\
\hline 1 & MLH1:NM_000249:c.1007G>A(p.G336D)(Exon11) Heterozygous & VUS \\
\hline 57 & MLH1:NM_000249:c.1897-17C $>\mathrm{G}($ Intron16) Heterozygous & VUS \\
\hline 4 & MLH1:NM_000249:c.2174G>A(p.R725H)(Exon19) Heterozygous & VUS \\
\hline 71 & MSH2:NM_000251:c.435T >G(p.I145M)(Exon3) Heterozygous & VUS \\
\hline 10 & MSH2:NM_000251:c.1254A>G(p.I418M)(Exon7) Heterozygous & VUS \\
\hline 54 & MSH2:NM_000251:c.1386+23T >G(Intron8) Heterozygous & VUS \\
\hline 36 & MSH2:NM_000251:c.2272G>A(p.D758N)(Exon14) Heterozygous & VUS \\
\hline 66 & MSH6:NM_000179:c.457+32_457+35delTGTG(Intron2) Heterozygous & VUS \\
\hline 65 & MSH6:NM_000179:c.3647-69_3647-65delTTTTG(Intron7) Heterozygous & VUS \\
\hline 45 & MSH6:NM_000179:c.4001+32_4001+35dupAACT(Intron9) Heterozygous & VUS \\
\hline
\end{tabular}

VUS: variant of uncertain significance 
was a pathogenic variant previously established in the same position [NM_000249:c.588+1G>T(HGMD: CS065593)] but substitutions were different. The patients who had a pathogenic variant in $\mathrm{MSH} 2$ gene did not have a positive family history, whereas the patients in whom pathogenic variants were found in $M L H 1$ gene did have a positive family history (Figure 1c).

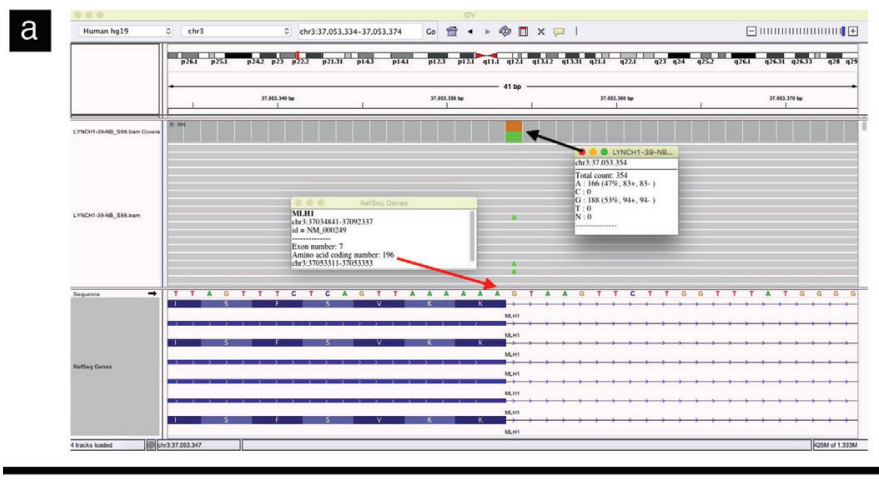

b
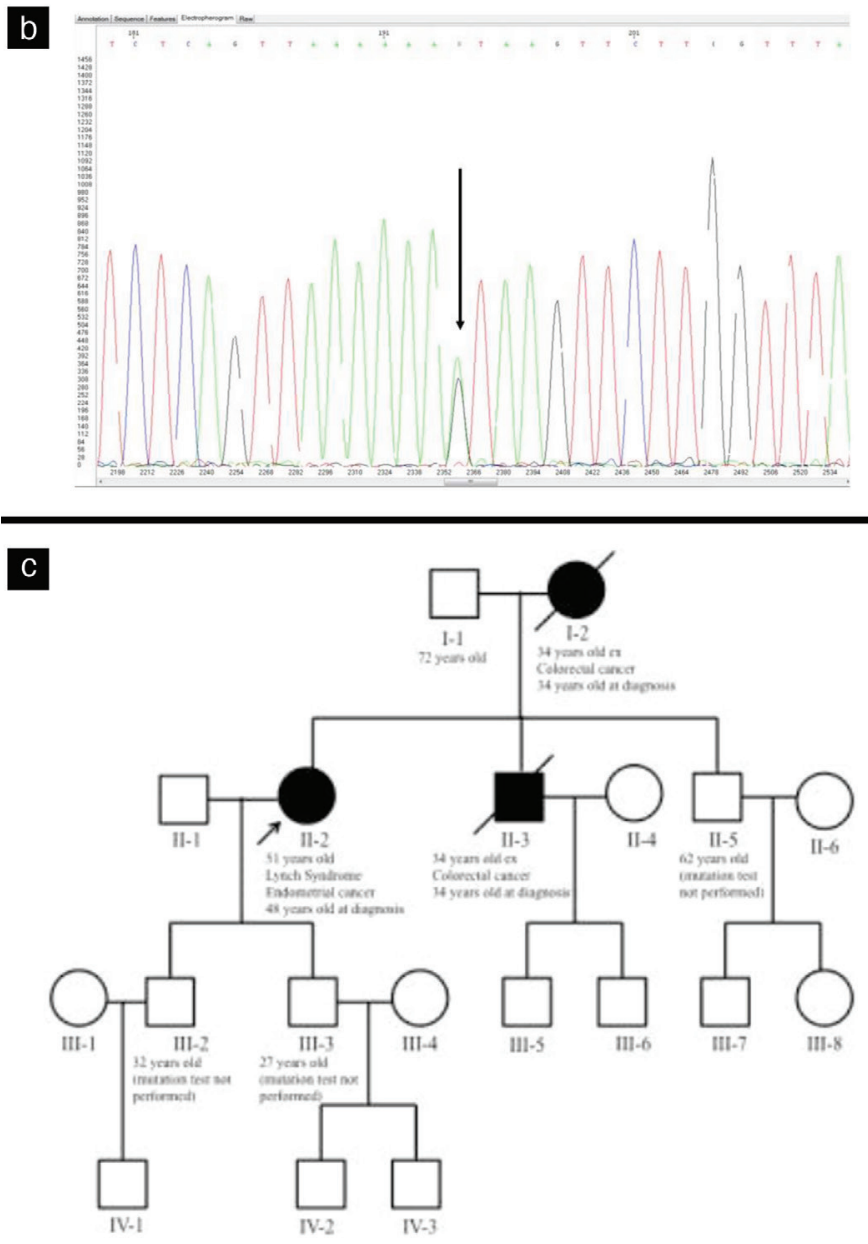

FIG. 1. a-c. IGV image (a), electropherogram (b) pedigree (c) patient no: 46 with a splice site variant [MLH1:NM_000249:c.588+1G $>$ A(Intron7) Heterozygous]. The black arrow indicates nucleotide change " $+1 \mathrm{G}>\mathrm{A}$ ". The red arrow indicates the last nucleotide of the exon 7 of $M L H 1$ gene.

IGV: integrative genomics viewer
Several studies were reported in the literature (Table 3); however, we could not find any NGS or Sanger sequencing studies in patients with endometrial cancer associated to Lynch syndrome in the Turkish population to compare with our study. Berends et al. (18) performed a mutation analysis of the $M L H 1, M S H 2$, and MSH6 genes using Sanger sequencing and MLPA techniques in 57 patients with endometrial cancer, who were younger than 50 years of age. They found 5 pathogenic germline mutations ( 1 in $M L H 1$, 3 in $M S H 2$, and 1 in MSH6) in 57 patients $(8.8 \% ; 5 / 57)$. In our study, we found 4 pathogenic variants in 79 patients $(5 \%$; 4/79). In another study, Goodfellow et al. (19) investigated only the MSH6 gene using sequencing. They performed microsatellite instability and $M L H 1$ methylation analyses in 441 endometrial cancer patients with no personal or family cancer history. They evaluated 100 cases $(23 \% ; 100 / 441)$ for the MSH6 gene and found 7 germline mutations. Finally, they estimated the minimum prevalence of the MSH6 mutation was $1.6 \%$ (7/441). We did not find any pathogenic variant in the MSH6 gene in our study. One of the reasons could be that all patients diagnosed were $<50$ years. Several studies have shown that endometrial cancer patients with the MSH6 germline mutations are associated with an older age (typically above 50 years) compared with $M L H 1$ and $M S H 2$ mutation carriers (19). The other study was performed by Ollikainen et al. (20). They screened MLH1, MSH2, MSH6 genes, and MLPA by Sanger sequencing in 32 cases among 519 consecutive patients with endometrial cancer. They found 11 mutations ( 6 in $M L H 1,4$ in MSH2, 1 in MSH6 genes). The minimum incidence of the MMR gene germline mutations was $2.1 \%(11 / 519)$ while in their study they found $0.3 \%$ (4 of 1094). One of the reasons could be that the PMS2 gene was not analyzed in this study. Hampel et al. (16) performed a large study that consisted of 543 endometrial cancer patients. They performed microsatellite instability testing in 543 tumors. One hundred eighteen $(21.7 \%)$ were microsatellite instability positive. They used sequencing and MLPA methods for analysis of the MLH1, MSH2 and MSH6 genes in 118 patients (MSI+). Ten mutations were identified ( 1 in $M L H 1,3$ in $M S H 2,6$ in MSH6 genes). The mean age of these patients was 54.6. They emphasized that at least $1.8 \%(10 / 543)$ of all endometrial cancer patients had Lynch syndrome. Four of the 81 patients $(4.9 \% ; 4 / 81)$ who were diagnosed under age 50 had Lynch syndrome, this was nearly identical to our findings $(5 \% ; 4 / 79)$. Lu et al. (21) performed a study consisting of 100 endometrial cancer patients diagnosed $<50$ years. $M L H 1, M S H 2$, and MSH6 genes were analyzed by sequencing and MLPA. They found 9 germline mutations (1 in MLH1, 7 in MSH2, 1 in MSH6 genes). The mean age at diagnosis was 41.6 years. In another study by Anagnostopoulos et al. (22), MMR germline mutation test was performed and they identified 3 pathogenic MMR mutations in 3 of 35 patients with endometrial cancer under age $50(8.5 \% ; 3 / 35)$.

Lynch syndrome patients and their relatives who have the same mutation can benefit from surveillance programs that could improve the chances of earlier diagnoses and reduce cancer risks (23-26). Prophylactic hysterectomy and bilateral salpingooophorectomy are recommended in patients with Lynch syndrome who have finished childbearing or have more than 40 years of age. Before taking this decision, patients should be evaluated 
TABLE 3. Summary of molecular analysis of MMR genes studies in patients with endometrial cancer

\begin{tabular}{|c|c|c|c|c|c|}
\hline Study (year) & Subjects & Genes & Methods & Results (mutations) & Mutation frequency \\
\hline $\begin{array}{l}\text { Berends et al. } \\
\text { (18) }\end{array}$ & $\begin{array}{l}57 \text { patients with endometrial cancer } \\
\text { diagnosed }<50 \text { years of age }\end{array}$ & $\begin{array}{l}\text { MLH1, MSH } 2, \text { MSH6 } \\
\text { (evaluated in } 57 \text { cases) }\end{array}$ & $\begin{array}{l}\text { Sanger sequencing } \\
\text { and MLPA }\end{array}$ & $\begin{array}{l}1 \text { in } M L H 1 \\
3 \text { in } M S H 2 \\
1 \text { in } M S H 6\end{array}$ & $8.8 \%(5 / 57)$ \\
\hline $\begin{array}{l}\text { Goodfellow et } \\
\text { al. (19) }\end{array}$ & $\begin{array}{l}441 \text { endometrial cancer patients } \\
\text { unselected for age }\end{array}$ & $\begin{array}{l}\text { MSH6 (evaluated for } 100 \\
\text { cases-see ref.) }\end{array}$ & Sanger sequencing & 7 in $M S H 6$ & $\begin{array}{l}\text { Minimum } 1.6 \%(7 / 441) \\
\quad \text { (only for MSH6) }\end{array}$ \\
\hline $\begin{array}{l}\text { Ollikainen et al. } \\
(20)\end{array}$ & $\begin{array}{l}519 \text { consecutive patients with } \\
\text { endometrial cancer }\end{array}$ & $\begin{array}{c}\text { MLH1, } M S H 2, \text { MSH6 } \\
\text { (evaluated for } 32 \text { cases- } \\
\text { see ref.) }\end{array}$ & $\begin{array}{l}\text { Sanger sequencing } \\
\text { and MLPA }\end{array}$ & $\begin{array}{l}6 \text { in } M L H 1 \\
4 \text { in } M S H 2 \\
1 \text { in } M S H 6\end{array}$ & Minimum 2.1\% (11/519) \\
\hline $\begin{array}{l}\text { Hampel et al. } \\
\text { (16) }\end{array}$ & $\begin{array}{c}543 \text { endometrial cancer patients } \\
\text { unselected for age ( } 81 \text { of } 543 \\
\text { diagnosed }<50 \text { years of age) }\end{array}$ & $\begin{array}{c}\text { MLH1, } M S H 2, \text { MSH6 } \\
\text { (evaluated for } 118 \text { cases- } \\
\text { see ref.) }\end{array}$ & $\begin{array}{l}\text { Sanger sequencing } \\
\text { and MLPA }\end{array}$ & $\begin{array}{l}1 \text { in } M L H 1 \\
3 \text { in } M S H 2 \\
6 \text { in } M S H 6\end{array}$ & $\begin{array}{c}\text { Minimum } 1.8 \%(10 / 543) \\
(4.9 \% ; 4 / 81 \text { diagnosed }<50 \\
\text { years of age })\end{array}$ \\
\hline Lu et al. (21) & $\begin{array}{l}100 \text { patients with endometrial } \\
\text { cancer diagnosed }<50 \text { years of age }\end{array}$ & $\begin{array}{l}M L H 1, M S H 2, M S H 6 \\
\text { (evaluated for } 100 \text { cases) }\end{array}$ & $\begin{array}{l}\text { Sanger sequencing } \\
\text { and MLPA }\end{array}$ & $\begin{array}{l}1 \text { in } M L H 1 \\
7 \text { in } M S H 2 \\
1 \text { in } M S H 6\end{array}$ & $9 \%(9 / 100)$ \\
\hline $\begin{array}{l}\text { Anagnostopoulos } \\
\text { et al. (22) }\end{array}$ & $\begin{array}{l}35 \text { patients with endometrial cancer } \\
\text { diagnosed }<50 \text { years of age }\end{array}$ & $\begin{array}{l}\text { MMR germline mutation } \\
\text { tests (evaluated for } 8 \\
\text { cases-see refs.) }\end{array}$ & $\begin{array}{l}\text { MMR germline } \\
\text { mutation tests (see } \\
\text { ref.) }\end{array}$ & $\begin{array}{l}3 \text { in MMR germline } \\
\text { mutation tests }\end{array}$ & $8.5 \%(3 / 35)$ \\
\hline In this study & $\begin{array}{l}1094 \text { consecutive patients with } \\
\text { endometrial cancer }\end{array}$ & $\begin{array}{c}\text { MLH1, MSH2, MSH6 } \\
\text { (evaluated for } 79 \text { cases- } \\
\text { see text) }\end{array}$ & $\begin{array}{l}\text { Targeted next } \\
\text { generation } \\
\text { sequencing }\end{array}$ & $\begin{array}{l}2 \text { in } M L H 1 \\
2 \text { in } M S H 2\end{array}$ & $\begin{array}{c}\text { Minimum } 0.3 \%(4 / 1094) \\
(5 \% ; 4 / 79 \text { diagnosed }<50 \\
\text { years of age })\end{array}$ \\
\hline
\end{tabular}

by the gynecologic oncologist. Colonoscopy screening is also recommended in affected persons and their first-degree relatives. In conclusion, endometrial cancer patients younger than 50 years of age should be evaluated for Lynch syndrome. Germline testing of MMR genes is required for definitive diagnosis of Lynch syndrome. This is the first Turkish study to present the experience of a single center in terms of revealing the mutation frequency of MMR genes using the NGS method in patients with endometrial cancer diagnosed $<50$ years. In the future, further studies are needed in larger groups.

Conflict of Interest: No conflict of interest was declared by the authors.

Financial Disclosure: No financial disclosure was declared by the authors.

\section{REFERENCES}

1. Win AK, Jenkins MA, Dowty JG, Antoniou AC, Lee A, Giles GG, et al. Prevalence and Penetrance of Major Genes and Polygenes for Colorectal Cancer. Cancer Epidemiol Biomarkers Prev 2017;26:404-12.

2. Lancaster JM, Powell CB, Chen LM, Richardson DL; SGO Clinical Practice Committee. Society of Gynecologic Oncology statement on risk assessment for inherited gynecologic cancer predispositions. Gynecol Oncol 2015;136:3-7.

3. Kwon JS, Scott JL, Gilks CB, Daniels MS, Sun CC, Lu KH. Testing women with endometrial cancer to detect Lynch syndrome. J Clin Oncol 2011;29:2247-52.

4. Hampel H, Bennett RL, Buchanan A, Pearlman R, Wiesner GL, Guideline Development Group, American College of Medical Genetics and Genomics Professional Practice and Guidelines Committee and National Society of Genetic Counselors Practice Guidelines Committee. A practice guideline from the American College of Medical Genetics and Genomics and the National Society of Genetic Counselors: referral indications for cancer predisposition assessment. Genet Med 2015; 17:70-87.

5. Kastrinos F, Uno H, Ukaegbu C, Alvero C, McFarland A, Yurgelun MB, et al. Development and Validation of the PREMM5 Model for Comprehensive Risk Assessment of Lynch Syndrome. J Clin Oncol 2017;35:2165-72.
6. Robinson JT, Thorvaldsdóttir H, Winckler W, Guttman M, Lander ES, Getz G, et al Integrative Genomics Viewer. Nat Biotechnol 2011;29:24-6.

7. Thorvaldsdóttir H, Robinson JT, Mesirov JP. Integrative Genomics Viewer (IGV): high-performance genomics data visualization and exploration. Brief Bioinform 2013;14:178-92.

8. Richards S, Aziz N, Bale S, Bick D, Das S, Gastier-Foster J, et al. Standards and guidelines for the interpretation of sequence variants: a joint consensus recommendation of the American College of Medical Genetics and Genomics and the Association for Molecular Pathology. Genet Med 2015;17:405-24.

9. Thompson BA, Spurdle AB, Plazzer JP, Greenblatt MS, Akagi K, Al-Mulla F, et al. Application of a 5-tiered scheme for standardized classification of 2,360 unique mismatch repair gene variants lodged on the InSiGHT locus-specific database. Nat Genet 2014;46:107-15.

10. Schwarz JM, Cooper DN, Schuelke M, Seelow D. Mutation Taster 2: mutation prediction for the deep-sequencing age. Nat Methods 2014;11:361-2.

11. Adzhubei IA, Schmidt S, Peshkin L, Ramensky VE, Gerasimova A, Bork P, et al. A method and server for predicting damaging missense mutations. Nat Methods 2010;7:248-9.

12. Kumar P, Henikoff S, Ng PC. Predicting the effects of coding non-synonymous variants on protein function using the SIFT algorithm. Nat Protoc 2009;4:1073-81.

13. Desmet FO, Hamroun D, Lalande M, Collod-Beroud G, Claustres M, Beroud C. Human Splicing Finder: an online bioinformatics tool to predict splicing signals. Nucleic Acids Res 2009;37:67.

14. Hutter P, Couturier A, Membrez V, Joris F, Sappino AP, Chappuis PO. Excess of hMLH1 germline mutations in Swiss families with hereditary non-polyposis colorectal cancer. Int J Cancer 1998;78:680-4.

15. Chong G, Jarry J, Marcus V, Thiffault I, Winocour S, Monczak Y, et al. High frequency of exon deletions and putative founder effects in French Canadian Lynch syndrome families. Hum Mutat 2009;30:797-812.

16. Hampel H, Frankel W, Panescu J, Lockman J, Sotamaa K, Fix D, et al. Screening for Lynch syndrome (hereditary nonpolyposis colorectal cancer) among endometrial cancer patients. Cancer Res 2006;66:7810-7.

17. Clarke BA, Cooper K. Identifying Lynch syndrome in patients with endometrial carcinoma: shortcomings of morphologic and clinical schemas. Adv Anat Pathol 2012;19:231-8. 
18. Berends MJ, Wu Y, Sijmons RH, van der Sluis T, Ek WB, Ligtenberg MJ, et al Toward new strategies to select young endometrial cancer patients for mismatch repair gene mutation analysis. J Clin Oncol 2003;21:4364-70.

19. Goodfellow PJ, Buttin BM, Herzog TJ, Rader JS, Gibb RK, Swisher E, et al Prevalence of defective DNA mismatch repair and MSH6 mutation in an unselected series of endometrial cancers. Proc Natl Acad Sci USA 2003;100:5908-13.

20. Ollikainen M, Abdel-Rahman WM, Moisio AL, Lindroos A, Kariola R, Järvelä I, et al Molecular analysis of familial endometrial carcinoma: a manifestation of hereditary nonpolyposis colorectal cancer or a separate syndrome? J Clin Oncol 2005;23:4609-16.

21. Lu KH, Schorge JO, Rodabaugh KJ, Daniels MS, Sun CC, Soliman PT, et al. Prospective Determination of Prevalence of Lynch Syndrome in Young Women with Endometrial Cancer. J Clin Oncol 2007;25:5158-64.

22. Anagnostopoulos A, McKay VH, Cooper I, Campbell F, Greenhalgh L, Kirwan J. Identifying Lynch Syndrome in Women Presenting With Endometrial Carcinoma Under the Age of 50 Years. Int J Gynecol Cancer 2017;27:931-7.
23. National Comprehensive Cancer Network: NCCN Clinical Practice Guidelines in Oncology: Colorectal Cancer Screening. Version 2. 2012: Accessed November 1, 2013. http://www.nccn.org/professionals/physician_gls/PDF/colorectal_screening. pdf.

24. Giardiello FM, Allen JI, Axilbund JE, Boland CR, Burke CA, Burt RW, et al Guidelines on genetic evaluation and management of Lynch syndrome: a consensus statement by the US Multi-society Task Force on colorectal cancer. Am J Gastroenterol 2014;109:1159-79.

25. Syngal S, Brand RE, Church JM, Giardiello FM, Hampel HL, Burt RW. ACG clinical guideline: Genetic testing and management of hereditary gastrointestinal cancer syndromes. Am J Gastroenterol 2015;110:223-62.

26. Herzig DO, Buie WD, Weiser MR, You YN, Rafferty JF, Feingold D, et al. Clinical Practice Guidelines for the Surgical Treatment of Patients With Lynch Syndrome. Dis Colon Rectum 2017;60:137-43. 